\section{Calculating Machines}

Recent and Prospective Developments and their Impact on Mathematical Physics ; Inaugural Lecture. By Prof. D. R. Hartree. Pp. $40+2$ plates. (Cambridge: At the University Press, 1947.) 2s, net.

7 HE rapid development of large-scale, high-speed calculating machines which has taken place in the United States in recent years is still not fully appreciated in Great Britain. These machines, in one form or another, are embodiments of Babbage's idea of an "analytical engine", and will undoubtedly have important effects both on numerical methods and on the attitude of the mathematical physicist to his problems. There is as yet no machine of this kind in Britain, though one is being planned at the National Physical Laboratory. The number of people from Great Britain who have seen the American machines is less than a dozen, and of these only one, Prof. D. R. Hartree, has actually worked the E.N.I.A.C., the electronic machine constructed at the University of Pennsylvania. This little book, therefore, has a particular importance. In this reprint of his inaugural lecture Prof. Hartree describes the E.N.I.A.C., and gives an account of the use he made of it in the solution of a set of non-linear differential equations with a two-point boundary problem. This gives him an opportunity to demonstrate vividly the remarkable speed of this type of machine, and to consider what features are desirable in such machines for general use in the field of mathematical physics.

The final section discusses the impact of these new developments on mathematical physics. The author suggests that not only will new mathematical developments be needed to devise new computing methods, but also that a new attitude to the problems of mathematical physics will be needed to make the best use of the facilities offered by this new type of equipment. In the author's own words, "It seems then quite possible that the facilities offered by these new calculating machines will at least make the formulation of physical problems in terms of integral equations and variation equations more familiar, and may in time wean us from our present tendency to regard a differential equation as the basic way of formulating the mathematics of physical problems".

\section{Chemistry for our Times}

By Elbert Cook Weaver and Dr. Laurence Standley Foster. Pp. xii +738. (New York and London : McGraw-Hill Book Co., Inc., 1947.) 12s. $6 d$.

$\mathrm{T}$ HE authors of this new elementary text-book aim at relating chemistry to everyday life, beginning with the immediate environment of the pupil and progressing from more to less familiar experiences. The basis is experimental, although modern theories, including very recent advances, receive adequate attention in their proper places. A special feature of the book is the wealth of illustration, all kinds of industrial plants being shown, as well as striking diagrams and very neat perspective drawings of apparatus. The text is well thought out, suitable revision being introduced from time to time, and the style is clear and attractive. Some organic chemistry is included. Problems are postponed until late, and the questions at the ends of the sections are aimed at stimulating thought rather than being tests of memory. Many anecdotes of the personalities of great discoverers are given, and the international character of science is well emphasized.
Although the book is elementary it is by no means superficial, a large amount of sound information being given in an interesting way; and care has been taken throughout to make the text intelligible and clear to any reader. We think any boy or girl be ginning the study of chemistry would be interester: by this book, and it could very usefully find a place. in any school or public library. The authors are to be congratulated on the result of what must have been a difficult piece of work. There are very few matters which should be altered in future editions, but among these it may be suggested that the information about the explosive properties of mixtures of hydrogen and air should come before, rather than after, the description of experiments with this gas; the date of Black's discovery of fixed air is twice given as 1775 instead of 1756 ; and the god Aeschylus in Fig. 21-21 should surely be Aesculapius. The very moderate price of the book is most commendable. This is an excellent elementary text-book which brings the modern developments in discovery into relation with classical material in a very skilful way.

\section{X-Rays in Research and Industry}

By Dr. H. Hirst. Second edition. Pp. vii +124. (London: Chapman and Hall, Ltd., 1946.) 13s. $6 d$. net.

GXCEPT for minor corrections, this book is identical with the first edition published in Australia and reviewed in these columns a few years ago. The book provides a concise introduction to the technique of X-ray diffraction and radiography, and to its applications particularly in physical metal. lurgy. An outstanding feature is the detail with which the author describes the practical details required by the experimenter, and it is to the practically minded reader that the book will most appeal. Every technique is not covered; but sufficient of the standard techniques is given to allow any worker entering this field to make a useful beginning. Since the first edition, other books have appeared which treat the same field of X-rays and metallurgy in a much more comprehensive manner. The present book will be found helpful, however, as a very readable and succinct introduction to these larger treatises.

W. A. WOOD

\section{Psycho-Analysis and its Derivatives}

By Dr. H. Crichton-Miller. (Home University Library of Modern Knowledge, No. 164.) Second Edition. Pp. 272. (London, New York and Toronto : Oxford University Press, 1945.) 3s. 6d. net.

7 HIS small book, which has deservedly been a very popular one, gives a strong, straightforward and simple account of the theories of the different schools of psycho-analysis. The three chief schools of Freud, Jung and Adler are all discussed in detail, and Prinzhorn added to them. The writer considers Freud's the most intricate, Jung's the most profound, Adler's the most practical and Prinzhorn's the broadest. Adler's system, of course, owing to its simplicity, attracts a great deal of attention, possibly owing to the appeal of the so-called 'inferiority complex' and of the fact that Adler pays little attention to dreams. Prinzhorn's use of lay analysts almost without limit to their activities is open to criticism, but may, because of this, appeal to a large number of people. There is a brief note on developments along various lines, and some account of Stekel's work published in 1940 . 